\title{
Capas de disco do rock brasileiro dos anos 1980: uma análise do uso das imagens das bandas
}

1980's Brazilian rock album covers: an analysis of the use of the bands' images

MORETTO, Paulo Eduardo; Doutorando; Faculdade de Arquitetura e Urbanismo - Usp

pmoretto@gmail.com

\begin{abstract}
Resumo
Este artigo apresenta um estudo sobre o design de capas de disco de vinil do rock brasileiro dos anos 1980, em especial as que trazem imagens dos integrantes das bandas (sejam fotografias ou ilustrações) como principais elementos da composição visual. Após situá-las em seu contexto histórico e cultural (momento em que houve grande projeção deste gênero musical e a consequente popularização destes discos de vinil), foram analisados os elementos gráficos que constituem essas capas, bem como sua recorrência na retórica visual da época, suas influências e referências visuais. Para tanto, foram usados relatos históricos e também estudos das teorias do design sobre linguagem visual.
\end{abstract}

Palavras Chave: capas de disco; rock brasileiro anos 1980; linguagem visual.

\begin{abstract}
This article presents a study on the design of Brazilian vinyl rock covers from the 1980's, especially those that use images of the bands (photographs or illustrations) as the main element of their visual compositions. After a historical and cultural contextualization (as this musical genre was widely spread at that time and led to the consequent popularization of its vinyl records), the graphic elements that constitute these covers were analyzed, as well as their recurrence in the visual rhetoric of that time, their influences and visual references. For this analysis, historical reports and design theories on visual language were used.
\end{abstract}

Keywords: album covers; Brazilian rock 1980's; visual language 


\section{Introdução}

A década de 1980 presenciou grandes mudanças que acabariam por reconfigurar o mundo, principalmente em termos políticos e sociais. No Brasil, esse processo ganhou peso ainda maior com o fim da ditadura militar, a redemocratização do país e uma forte estagnação econômica. A crescente importância dada aos jovens nas culturas ocidentais desde o fim da Segunda Guerra Mundial garantiu a estes relevância nunca antes experimentada. Tal situação fez com que a indústria e o comércio direcionassem seus esforços de produção e venda, principalmente em momentos de crise, a esse público. A cena cultural e musical apresentou, então, seus novos protagonistas, com destaque para as bandas de pop rock, menos contestadoras e mais sarcásticas. A indústria fonográfica viveu seu auge, que antecederia a crise das décadas seguintes. As capas dos discos de vinil, dada sua visualidade, ganharam assim espaço especial no imaginário daquela época e tornaram-se um de seus ícones.

\subsection{Contextualização histórica}

Ao longo do século $X X$, o design ganhou paulatinamente espaço na vida das pessoas e tornou-se parte integrante do seu dia a dia, sendo incorporado, por meio de suas várias manifestações, aos objetos cotidianos como mobiliário, roupas, livros e revistas (WOLLNER, 2002).

Essa inserção no cotidiano garantiu ao design (seja de objetos, seja gráfico) a capacidade de refletir a sociedade na qual se insere, não só dando forma ao seu imaginário coletivo, mas também evidenciando suas necessidades, aspirações e realizações. Marcas, embalagens, rótulos, etiquetas de produtos, placas de sinalização viária, livros, revistas ou, até mesmo, cartões de visita passam a fazer parte do repertório visual das pessoas num dado momento. Produtos de escala generosa, como cartazes e capas de discos de vinil, que interagem com o homem na escala de seu corpo, têm destaque nessa formação do imaginário coletivo (MORETTO, 2004).

Os anos 1980, foco deste trabalho, foram marcados por aspectos políticos e tecnológicos significativos, com o correspondente impacto sobre o design e a música popular. O Brasil vivia um momento único, com o fim da ditadura militar e o movimento pelas eleições diretas, enquanto que, na cena musical, o país presenciava a ascensão de bandas jovens de pop rock, menos contestadoras, mais sarcásticas e comerciais (ALZER; CLAUDINO, 2004).

No cenário mundial também ocorreram mudanças políticas que acabariam, no final da década, ocasionando a queda do Muro de Berlim e o fim da Guerra Fria, com reflexos transformadores nas sociedades e culturas mundiais. A derrocada das grandes narrativas (LYOTARD, 1993) abriu as portas para o Pós-Modernismo e novas possibilidades estéticas e artísticas, com mais espaço para experimentações.

No campo da tecnologia, o computador pessoal (PC) ganhou espaço, popularizou-se e, no decorrer de uma década, transformaria radicalmente o modo de trabalhar dos designers. No Brasil, esse processo de assimilação do computador foi acompanhado por uma profissionalização do ofício do designer gráfico, decorrente em parte do aumento no número de egressos dos cursos de design iniciados no país nas duas décadas anteriores (HOMEM DE MELO, 2011).

Apesar da crise, a indústria fonográfica vivia um grande momento, com o surgimento de inúmeras bandas e recordes de vendas. As transformações tecnológicas, no entanto, preconizavam a substituição do disco de vinil pelo compact disc (CD) que, em meados da década seguinte, já dominaria o mercado e mudaria totalmente a relação dos consumidores com a música e seus 
suportes físicos. Em menos de quinze anos, viveu-se o apogeu e o declínio da produção de discos de vinil e de suas idolatradas capas.

A crescente importância dada aos jovens nas culturas ocidentais desde o fim da Segunda Guerra Mundial ganhou contornos mais definitivos na década de 1980, garantido a estes protagonismo nunca antes experimentado. Tal situação fez com que a indústria e o comércio canalizassem seus esforços de produção e venda, principalmente em momentos de crise, para esse público. Isso, em parte, explica a valorização cultural experimentada pelas bandas de pop rock e seus discos no Brasil naquele momento. As capas dos discos de vinil, dada sua visualidade, ganharam assim espaço especial no imaginário daquela época.

\subsection{Contextualização musical}

Nos anos 1970, o Punk Rock levou o Rock \& Roll de volta para o básico - três acordes e uma melodia simples - só que mais alto, mais rápido e mais agressivo do que no passado. Embora houvesse várias bandas flertando com o que se tornaria conhecido como Punk Rock, foi somente em meados dos anos 70 que este se tornou um gênero autônomo. Em ambos os lados do Atlântico, as bandas jovens começaram a abandonar os excessos sonoros que caracterizavam o Hard Rock e despojaram a música até o essencial. Surge, em Nova York, a primeira banda punk, o Ramones, e, em Londres, o Sex Pistols (VINIL, 2008).

Embora as duas bandas tivessem propostas e sons diferentes, a abordagem direta de ambas revolucionou a música nos dois países. Na América, o Punk permaneceu alternativo, underground, mas no Reino Unido, foi um fenômeno de grande escala, com implicações sócio-político-culturais, como a cultura do "faça você mesmo" (do it yourself). Os Sex Pistols causavam desconforto ao governo conservador de Margaret Thatcher, bem como à monarquia inglesa, mas, acima de tudo, provocaram a formação de inúmeras outras bandas.

Gradativamente, o Punk derivou, em termos macroscópicos, em três vertentes: o Pós-punk, que era mais experimental e mais conceitual do que o Punk; o New Wave, que era mais pop, mais dançante, performático e fazia uso abusivo de sintetizadores; e o Hardcore, que simplesmente tornava o Punk mais pesado, mais rápido e ainda mais agressivo. Vale ressaltar que, durante algum tempo, no final dos anos 1970 e início dos anos 1980, New Wave era um termo genérico e controverso para designar a música que derivou diretamente do Punk Rock e, muitas vezes, por questões mercadológicas, englobava também o próprio Punk e o Pós-punk.

No Brasil, apesar de toda a dificuldade que se tinha na época para se ter acesso à produção musical estrangeira, os jovens dos grandes centros urbanos estavam atentos à cena sociocultural internacional, principalmente a londrina e a nova iorquina. Discos, ou cópias em fitas cassetes, de bandas como Sex Pistols, Clash, Police ou Ramones, New York Dolls, Talking Heads e B-52's, circulavam entre as casas, as salas de aula ou as festas de diferentes classes sociais e também provocaram, em terras brasileiras, o surgimento de bandas de rock formadas por jovens cansados do domínio musical imposto pela Bossa Nova, pela MPB e, até mesmo, pela Tropicália nas décadas anteriores (1960 e 1970) (ALEXANDRE, 2002).

A indústria fonográfica foi à caça de novos talentos e atirou para todos os lados. Várias são as bandas que tiveram um único disco lançado, ou, até mesmo, um só único sucesso (hit), e depois foram devolvidas ao anonimato. Por questões econômicas e comerciais, jovens de São Paulo e do 
Rio de Janeiro tinham maiores chances de realizar o sonho de ter o primeiro álbum de sua banda prensado e lançado.

As primeiras bandas de Pop Rock a fazerem sucesso na década foram a paulistana Gang 90 e as Absurdettes, com o hit "Perdidos na selva" (inscrita no festival MPB Shell 81) e liderados pelo jornalista Júlio Barroso, e a carioca Blitz, formada no Circo Voador em torno do grupo teatral Asdrúbal Trouxe o Trombone e que tornou-se um fenômeno através do sucesso "Você não soube me amar" (DAPIEVE, 1995).

O rock brasileiro dos anos 1980, hoje genericamente denominado de BRock, foi feito por bandas das mais distantes partes do país e com as mais variadas influências musicais, garantindo não só um amplo espectro musical, mas também uma grande diversidade visual do figurino de seus integrantes e das capas de seus discos. Poderíamos dizer que, grosso modo, as bandas cariocas, por exemplo, pareciam estar mais atentas ao New Wave, adotando um visual mais extrovertido e de cores vibrantes, enquanto que as bandas paulistanas e brasilienses, com forte influência do Punk e do Pós-punk, acabavam adotando o preto e os cinzas, reforçados por uma postura mais soturna e agressiva (ALEXANDRE, 2002).

\section{Considerações teóricas e metodológicas}

A partir de um levantamento preliminar em publicações como Almanaque anos 80 (ALZER; CLAUDINO, 2004) e Almanaque do rock (VINIL, 2008), assim como em outros livros que versam sobre esse momento histórico e musical, como Dias de luta: o rock e o Brasil dos anos 80 (ALEXANDRE, 2002) e BRock: o rock brasileiro dos anos 80 (DAPIEVE, 1995), pôde-se levantar várias das bandas que protagonizaram essa história, como Blitz, Barão Vermelho, Paralamas do Sucesso, Titãs, Ultraje a Rigor ou Legião Urbana, e outras menos conhecidas, como Hanói Hanói, Metrô, Magazine, Zero, Picassos Falsos, Os Replicantes, DeFalla, Finis Africae, Detrito Federal, Fellini, Violeta de Outono, Gueto, Muzak, Nau, Mercenárias e Golpe de Estado, entre tantas outras.

Buscou-se, então, identificar as capas dos discos lançados por essas bandas no período estudado, e constituiu-se um universo de 83 peças gráficas (quadro 1), ressaltando que grande parte dessa produção ocorreu nos anos de 1985 a 1989. Interessante notar também que, no ano de 1987, concentram-se muitos desses lançamentos do chamado BRock, fato também ressaltado por Kid Vinil em seu almanaque.

Para analisar o material recolhido, recorreu-se a alguns estudos teóricos sobre design gráfico, linguagem e análise visual de peças gráficas. Em Novos fundamentos do design (LUPTON; PHILLIPS, 2008), as autoras apresentam princípios básicos para se criar e analisar a imagem visual, bem como as relações que se estabelecem entre seus elementos constitutivos, organizando um lexo universal para se pensar o design gráfico.

Outro estudo que norteou a leitura aqui apresentada foi o de Isabella Aragão (2011) sobre os rótulos de cachaça de Pernambuco que, pautada na análise que o tipógrafo e teórico inglês Michael Twyman (1986) fez sobre os elementos pictóricos, verbais e esquemáticos encontrados em materiais impressos, propôs a ideia de analisar tais elementos a partir dos conceitos de plural e singular. Os elementos visuais plurais seriam os comumente usados na criação de peças gráficas de um determinado momento e lugar (padrões herméticos da prática gráfica de uma época) e, os singulares, antagonicamente, os elementos visuais únicos que particularizam algumas dessas composições visuais, sem repercussão no conjunto. 
Quadro 1 - Conjunto levantado de capas dos discos do BRock distribuídas cronologicamente.
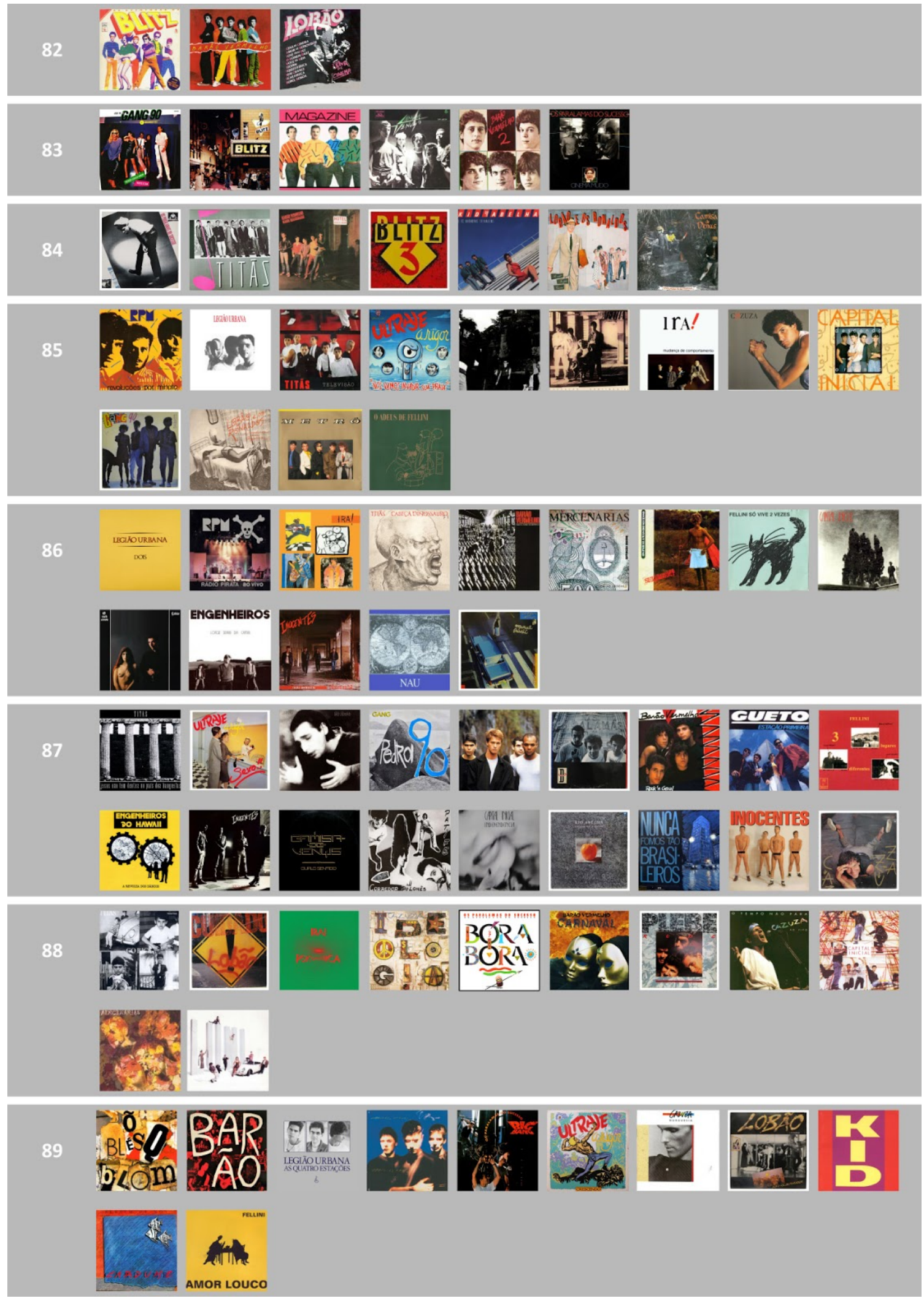

Fonte: elaborado pelo autor com base no levantamento realizado. 


\section{Análise preliminar}

Apesar de se apresentar aqui um recorte parcial das capas de disco de rock nacional produzidas na década de 1980, pôde-se identificar alguns aspectos plurais no design dessas peças gráficas, a partir da análise de seus elementos pictóricos, verbais e esquemáticos.

O primeiro aspecto que chama a atenção é que a maioria das capas apresenta um elemento pictórico dominante na composição (usualmente uma fotografia em preto e branco ou uma ilustração retratando os integrantes da banda) e dois elementos verbais (o nome da banda e o título do álbum). Quando coincidentes, os dois elementos verbais são grafados uma única vez, normalmente usando-se tipografias comerciais ${ }^{1}$ e, ocasionalmente, em algumas das capas, letras vernaculares e manuscritas.

Outra característica recorrente é que o nome da banda costuma ser o elemento verbal principal, ocupando a parte superior da capa, enquanto que o título do álbum, muitas vezes grafado num corpo menor (e em outra tipografia), costuma ter menos destaque e ocupa a parte inferior junto à borda da capa. Algumas poucas vezes os elementos verbais foram tratados integradamente aos pictóricos (quase como se fossem imagens), mas normalmente esses se sobrepõem às fotografias e ilustrações que lhe servem de fundo.

Não se observou um estilo predominante, nem quanto aos elementos pictóricos usados ou quanto às tipografias adotadas e nem em relação à existência de uma paleta de cores comum ao conjunto das capas, mas notou-se o predomínio de brancos, pretos, cinzas e cores não vibrantes.

\section{Capas em estudo}

Dentre os vários aspectos levantados a partir da análise do material selecionado, observa-se que mais da metade das capas estudadas, 48 (quadro 1), apresentam como solução de comunicação visual o uso de imagens dos integrantes das respectivas bandas, muitas vezes com esses em poses semelhantes, quase como se existisse uma obrigatoriedade de se usar essas imagens para criar essas capas e, mais do que isso, como se existisse uma fórmula hegemônica de como retratar essas bandas.

Poderia-se especular se tais soluções visuais foram concebidas em resposta a uma demanda específica, seja da gravadora, seja da banda, visando atender ao mercado ou à necessidade intuída pelos músicos de serem conhecidos junto a seu público. Outra possibilidade seria atribuir tais soluções ao "espírito" dos anos 1980 se manifestando visualmente e fazendo com que diferentes designers propusessem capas muito parecidas.

Tradicionalmente, o design de capas de disco para a MPB, e para o próprio rock nacional, apresentava o(a) cantor(a) ou os integrantes das bandas, como em Os Mutantes de 1968, Secos e Molhados de 1973 e Doces Bárbaros de 1976, todos álbuns de bandas homônimas - figuras 1, 2 e 3 , respectivamente. Nas capas de disco aqui em estudo, nota-se a renovação desta tradição, com a assimilação de outras referências visuais (MUNARI, 1987) provindas de bandas de rock inglesas e americanas que serviam de referência musical para os músicos do rock nacional dos anos 1980 .

\footnotetext{
${ }^{1}$ Fontes e famílias tipográficas padronizadas e comercializadas para o uso na composição de diferentes peças gráficas.
} 


\section{Artigo Completo}

Figura 1, 2 e 3 - Capas dos discos: Mutantes (1968), Secos e Molhados (1973) e Doces Bárbaros (1976).
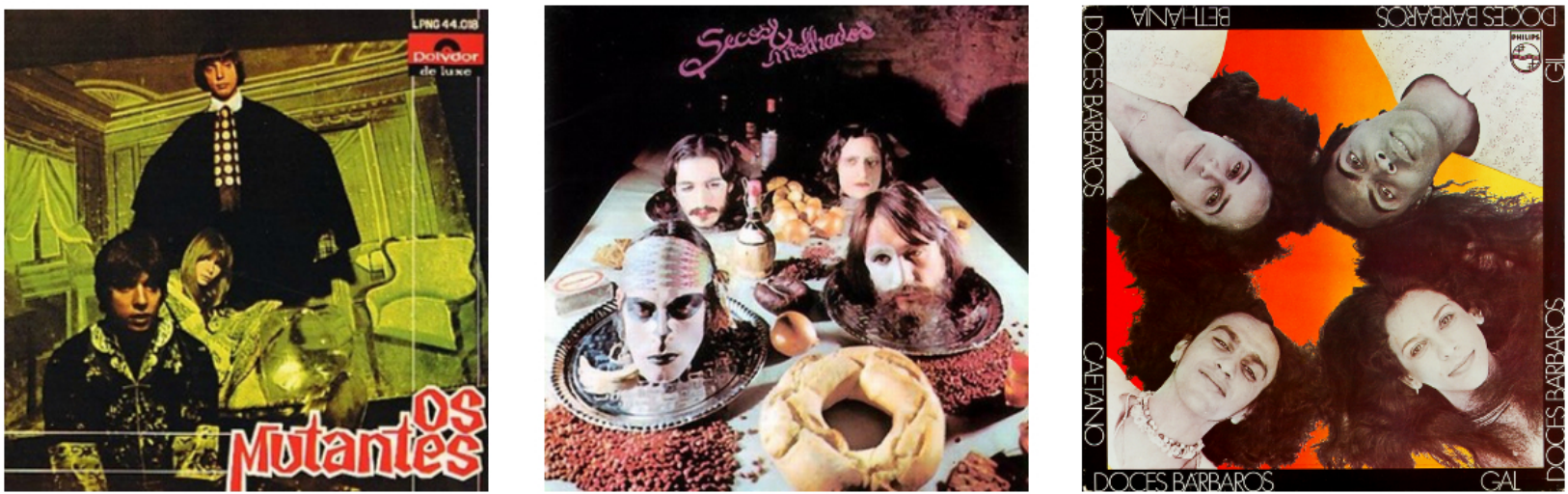

Fonte: reprodução dos originais feitas pelo autor.

Interessante notar como capas de discos como a dos Ramones (1976), a dos Buzzcocks (1978) ou a do B-52's (1979) - figuras 4, 5 e 6 - parecem terem servido de inspiração para as capas do BRock. Com essas novas referências, as fotografias das capas estudadas distinguem-se pelo enquadramento e pela postura, com certo desdém desafiador dos retratados encarando a câmera.

Figuras 4, 5 e 6 - Capas dos discos: Ramones (Ramones, 1976),

Buzzcocks (Buzzcocks: another music in a different kitchen, 1978) e B-52's (B-52's, 1979).
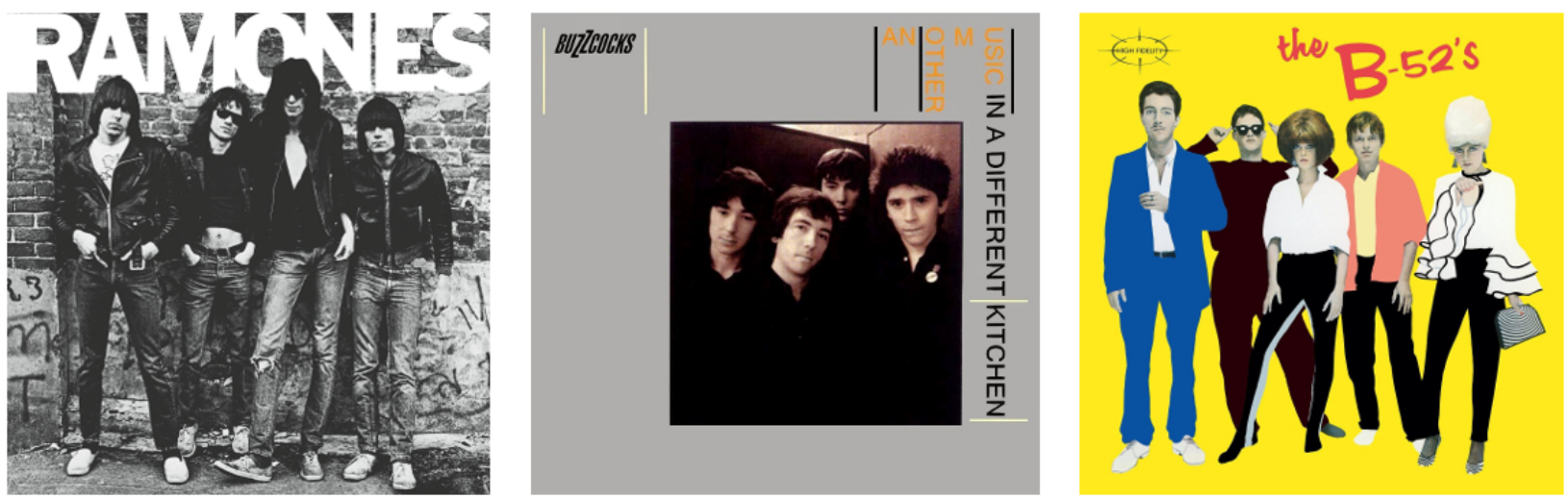

Fonte: reprodução dos originais feitas pelo autor.

Um olhar mais atento a essas capas estudadas nas quais foram utilizadas imagens dos integrantes das bandas como elemento pictórico principal, percebe-se alguns subgrupos de elementos plurais que serão identificados abaixo e exemplificados com a análise visual de capas representativas desses mesmos conjuntos identificados.

\subsection{Capas com retratos das bandas em fundo neutro}

Uma das soluções mais recorrentes no design de capas de disco para bandas de rock nacional nos anos 1980 é o uso de retrato, normalmente fotográfico, dos músicos em um fundo neutro, muitas vezes centralizado na composição, com ou sem moldura, como pode-se observar nas figuras 7, 8 e 9. Os elementos verbais, como o nome da banda e o do álbum, quase sempre ocupam, respectivamente, as regiões superiores e inferiores próximas às bordas das capas. 
Figuras 7, 8 e 9 - Capas dos discos: Gang 90 \& Absurdettes (Essa tal de Gang 90 e as Absurdettes, 1983); Legião Urbana (Legião Urbana, 1985) e Capital Inicial (Todos os lados, 1989).
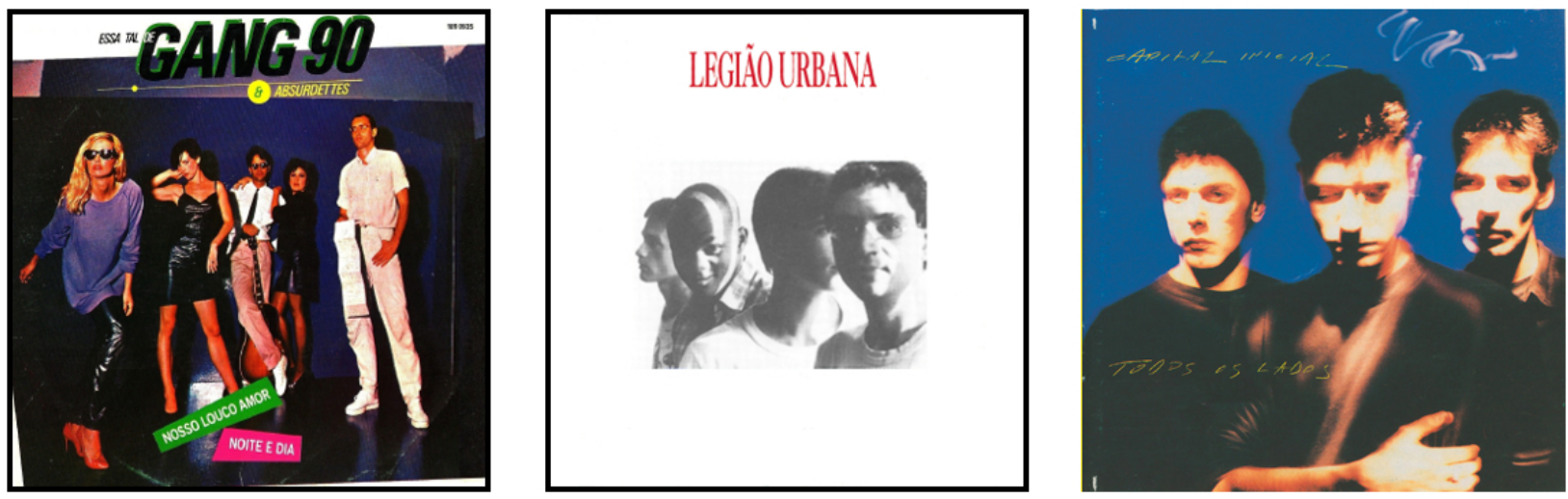

Fonte: reprodução dos originais feitas pelo autor.

Legião Urbana é o primeiro álbum da banda brasiliense homônima lançado em 1985 pela EMI-Odeon (figura 8). Esta capa exemplifica bem este tipo de solução e organiza-se em torno de uma fotografia PB que ocupa o seu centro, sobre um fundo branco que a emoldura, e apresenta os quatro integrantes da banda em diferentes planos. Um jogo de luz e sombras, além de um certo desfoque, faz com que seus rostos se misturem, tornando difícil a identificação dos músicos. Outros dois elementos pictóricos foram colocados acima e abaixo da fotografia: a silhueta do edifício do Congresso Nacional (em Brasília) e a silhueta de um índio com arco e flecha, respectivamente. Ambos os elementos foram impressos em alto-relevo seco (sem o uso de tinta), tornando-os quase que imperceptíveis quando vistos à distância. $\mathrm{O}$ mesmo tratamento foi dado a imagem de um lacre de lata de refrigerante na contracapa, o que abre espaço para diferentes interpretações num disco que trazia canções com críticas à política e ao status quo como "Soldados" e "Geração Coca-Cola". Ocupando cerca de um terço da largura da parte superior da capa, próximo à borda, encontra-se o principal elemento verbal (título e nome da banda), composto em caixa alta numa fonte serifada, condensada, impressa em alto-relevo americano (com tinta na cor vermelha), o que lhe garante destaque na composição. A mesma composição tipográfica é repetida outras duas vezes, dispostas verticalmente nas bordas esquerda e direita da capa, mas agora em relevo seco, deixando-os menos evidentes. A aparência geral é de, apesar dos vários elementos descritos, um certo minimalismo e limpeza visual. A capa foi feita por Ricardo Leite, designer muito atuante na indústria fonográfica nos anos 1980.

\subsection{Capas com retratos das bandas em um cenário}

Outras soluções recorrentes, e semelhantes às anteriormente descritas, são as que fazem uso de retratos fotográficos dos músicos, mas aqui posando em algum cenário que contextualiza a capa e o álbum (figuras 10, 11 e 12). Essas imagens são muitas vezes centralizadas na composição, com ou sem uma moldura, e os elementos verbais, como o nome da banda e o do álbum, costumam ocupar, respectivamente, as regiões superiores e inferiores próximas às bordas das capas, mas existem exceções, como nota-se na figura 12, na qual o título do álbum encontra-se também na parte superior da capa . 


\section{Artigo Completo}

Figuras 10, 11 e 12 - Capas dos discos: Os Paralamas do Sucesso (Cinema mudo, 1983), Kid Abelha e os Abóboras Selvagens (Educação sentimental, 1985) e Gueto (Estação primeira, 1987).
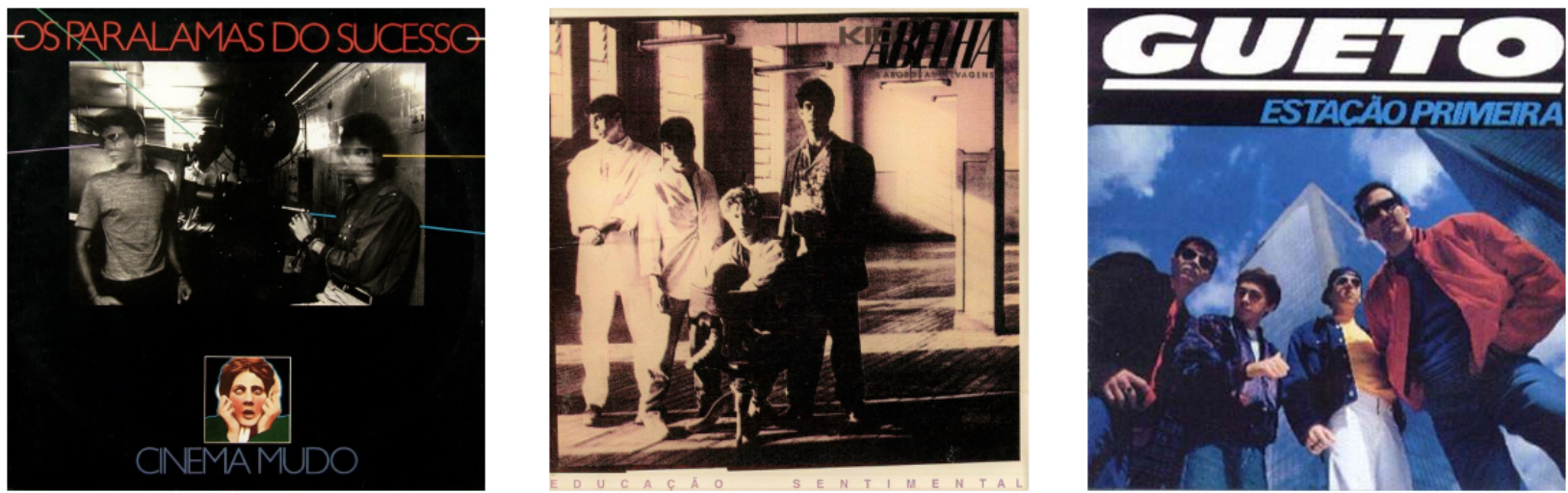

Fonte: reprodução dos originais feitas pelo autor.

O álbum Cinema Mudo da banda Os Paralamas do Sucesso foi lançado em 1983 pela EMI-Odeon (figura 10). Os elementos visuais desta capa a contextualizam numa sala de cinema, onde a banda parece ser apresentada na tela. Sua composição está organizada em torno de dois elementos pictóricos: o primeiro é uma foto em preto e branco da banda dentro de uma cabine de projeção de cinema que ocupa a metade superior da capa. Apesar de ser a primeira aparição da banda no seu primeiro álbum, a foto não se pretende um "retrato"; ao invés disso, os músicos parecem estar em movimento, como se se tratasse de um momento fugaz da banda, sublinhando a conexão com a ideia de cinema. Quatro linhas ornamentais finas e de diferentes cores (elementos esquemáticos) saem dos olhos e do projetor em direção à borda da capa. Logo acima da foto, próximo à borda superior da capa, encontra-se o nome da banda (elemento verbal principal), composto em caixa alta numa fonte sem serifa, geométrica e na cor vermelha, ocupando toda a largura da capa, o que, sobre o fundo preto, garante-lhe grande destaque. 0 segundo elemento pictórico encontra-se logo abaixo do primeiro: em tamanho menor, apresenta-se ilustração colorida que, junto com o título do álbum, que se encontra abaixo desta, entende-se ser uma personagem dos filmes do cinema mudo (fato que se confirma na contracapa onde várias outras ilustrações, intercaladas com fotos PB dos músicos, apresentam a mesma mulher com diferentes expressões faciais e legendas como "horror", "determinação" ou "piedade", fazendo alusão às vinhetas típicas desse gênero cinematográfico). O texto do título do álbum foi composto na mesma fonte do nome da banda, também em caixa alta, mas num corpo um pouco menor e numa cor lilás suave, de pouco contraste com o fundo. $O$ design da capa e as ilustrações foram feitas por Ricardo Leite, autor de quase todas as capas da banda naquela década.

\subsection{Capas com retratos das bandas ilustrados ou com intervenções gráficas}

Outro grupo de soluções faz uso da imagem fotográfica das bandas como base para ilustrações ou intervenções gráficas. As imagens resultantes são usadas nas composições visuais das capas de maneira muito semelhante como nas demais soluções descritas anteriormente, isto é, centralizadas na composição, com ou sem uma moldura, e os elementos verbais, como o nome da banda e o do álbum, também ocupando, respectivamente, as regiões superiores e inferiores próximas às bordas das capas. Novamente, pode-se encontrar exceções, como na figura 13, na 
qual parte do título do álbum coincide com o nome da banda, Blitz, que foi grafado uma única vez, numa tipografia tridimensional, ambos na parte superior da capa.

Figuras 13, 14 e 15 - Capas dos discos: Blitz (As aventuras da Blitz, 1982), RPM (Revoluções por minuto, 1985) e Mercenárias (Trashland, 1988).
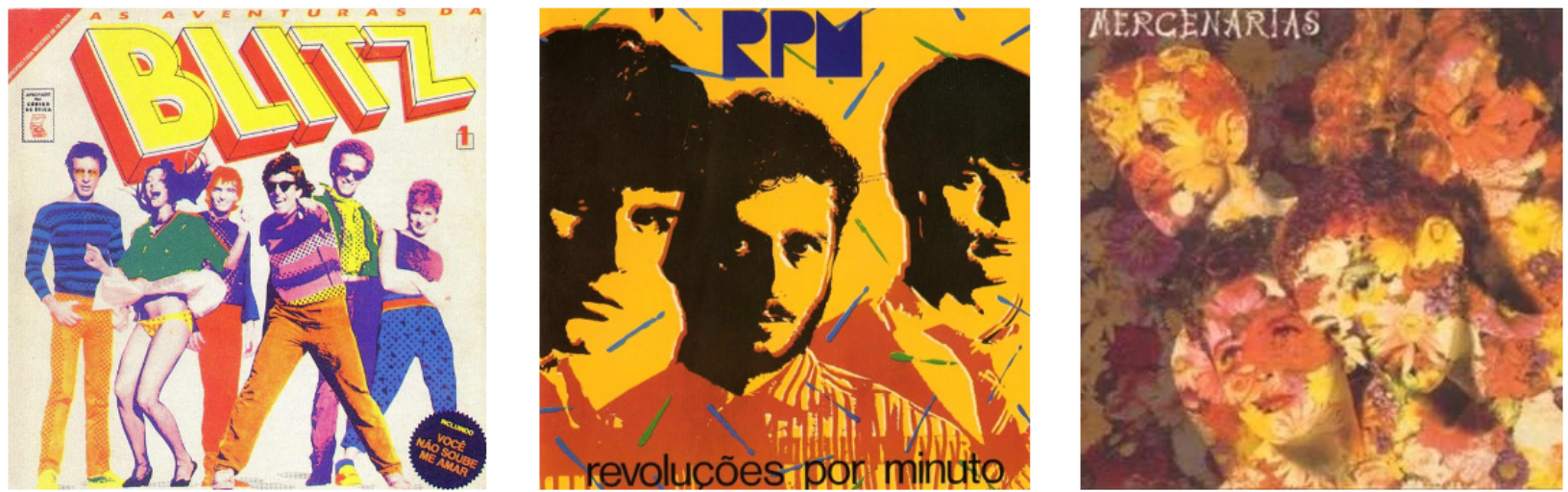

Fonte: reprodução dos originais feitas pelo autor.

Revoluções por Minuto (figura 14) é o primeiro álbum de estúdio da banda de rock paulista RPM, lançado pela gravadora CBS (selo Epic). A composição visual da capa é dominada por um único elemento pictórico: sobre um fundo amarelo alaranjado, uma ilustração em estêncil (feita a partir do alto-contraste de uma foto) apresenta o retrato de três dos quatro integrantes da banda encarando a câmera em primeiro plano. As cores predominantes, além do amarelo, são o marrom escuro e o vermelho terra, com alguns detalhes em branco. A imagem tem a interferência de riscos disformes inclinados em verde e em azul (elementos esquemáticos) que formam um padrão irregular que é interrompido para preservar os rostos dos músicos. Dois elementos verbais completam a composição: o nome da banda aparece na parte superior, no centro, numa fonte fantasia ${ }^{2}$ estêncil (provavelmente criada especialmente para a capa) na cor azul-marinho. Já o título do álbum ocupa quase toda a largura do campo gráfico na sua borda inferior e foi grafado em caixa baixa com tipografia sem serifa e em preto. O uso da técnica do estêncil, junto com as cores vibrantes escolhidas, trouxe ao álbum o clima urbano e contemporâneo do graffiti (muito usado para manifestações ideológicas e artísticas nos muros das cidades), reforçando a identidade da banda que apresentava um pop rock dançante e "politizado". Tanto o nome da banda quanto o título do álbum fazem alusão à unidade de medida da velocidade de rotação dos discos, revoluções (rotações) por minuto, numa tradução direta do inglês, revolutions per minute, e que, em português, ganha um sentido dúbio. $O$ álbum chegou às lojas logo após a morte de Tancredo Neves, em 1985, e seu misto de letras sobre paixões platônicas, declarações de amor com política internacional e transformações socioeconômicas garantiu o seu sucesso, emplacando uma sequência de hits nas rádios (oito de suas onze faixas) e vendendo 100 mil cópias na época (disco de ouro) e mais de 300 mil cópias desde então. Com direção de arte de Geraldo Alves Pinto e Ricardo Leite, a ilustração é do artista plástico Alex Flemming e é certamente um dos ícones visuais dos anos 1980.

\footnotetext{
${ }^{2}$ Fonte tipográfica com desenho peculiar dos caracteres, normalmente feito para o uso em títulos ou em peças gráficas específicas, como cartazes, folhetos ou capas de livros, e de difícil aplicação em texto corrido devido a sua baixa legibilidade. Também conhecidas como Fontes Display.
} 


\section{Considerações finais}

Como mencionado anteriormente, este é um estudo de parte da produção de capas de disco do rock brasileiro dos anos 1980 e, portanto, apresentou-se aqui uma análise do material levantado, mas que é parcial, sujeitando-a a futuras revisões e novas interpretações. Vale notar também que foram analisados alguns aspectos específicos sobre os elementos pictóricos principais das composições visuais das capas e, mais especificamente, das capas que apresentavam como elemento pictórico principal imagens (fotografias ou ilustrações) dos integrantes das bandas.

Para se entender e aprofundar o estudo desta produção visual, pretende-se identificar e analisar outras soluções recorrentes no design de capas do rock nacional dos anos 1980, detalhando-se os demais elementos visuais que constituem a retórica visual dessa época. Pode-se inferir que a análise de um número maior dessas capas, bem como de outros gêneros, origens e épocas, ajudará a distinguir o que é plural ou singular no design de capas de vinil em geral e no que diz respeito a este conjunto.

Podem ser interessantes também futuras investigações sobre como os elementos aqui descritos e analisados foram percebidos e agregados à memória (afetiva) das pessoas que viveram naquela época, bem como a sua incorporação ao léxico visual dos designers gráficos e sua influência no processo criativo deles e a permanência (ou pregnância) desses na retórica visual usada para a criação de capas de disco de rock de décadas posteriores ou de capas de outros gêneros musicais.

\section{Referências}

ALEXANDRE, Ricardo. Dias de luta: o rock e o Brasil dos anos 80. Porto Alegre: Arquipélago Editorial, 2013.

ALZER, Luiz André; CLAUDINO, Mariana. Almanaque anos 80. Rio de Janeiro: Ediouro, 2004. ARAGÃO, Isabella. "O plural e o singular nas composições visuais dos rótulos de bebida". In: CAMPELLO, Silvio \& ARAGÃO, Isabella (eds.) Imagens comerciais de Pernambuco: ensaios sobre os efêmeros da Guaianases, pp. 93-113, 2011.

DAPIEVE, Arthur. BRock: o rock brasileiro dos anos 80. São Paulo: Editora 34, 1995.

HOMEM DE MELO, Chico \& RAMOS, Elaine. Linha do tempo do design gráfico no Brasil. São Paulo: Cosac Naify, 2011.

LUPTON, Ellen; PHILLIPS, Jennifer Cole. Novos fundamentos do design. São Paulo: Cosac Naify, 2008.

LYOTARD, Jean-François. 0 pós-moderno explicado às crianças: correspondência 1982-1985. Lisboa: Dom Quixote, 1993.

MORETTO, Paulo E.. Cartazes de propaganda cultural no Brasil: Cinco décadas de técnicas e linguagem . Dissertação de mestrado. São Paulo: FAUUSP, 2004.

MUNARI, B. Fantasia: invenção, criatividade e imaginação na comunicação visual. Lisboa: Presença, 1987. 


\section{Artigo Completo}

TWYMAN, Michael. "Articulating graphic language: a historical perspective". In: WROLSTAD, Merald E.; FISCHER, Dennis F. (orgs.). Toward a new understanding of literacy. New York: Praeger Publishers, p.188-251, 1986.

VINIL, Kid. Almanaque do rock. São Paulo: Ediouro, 2008.

WOLLNER, A. "Comunicação Visual". In: ZANINI, W. (org). História geral da arte no Brasil, vol. 1. São Paulo: Instituto Walther Moreira Salles, 1983. 